\title{
PRÉ-CONSTRUÇÃO DIGITAL DA CONSTRUÇÃO - IMPLEMENTAÇÃO NO GRUPO CASAIS
}

\author{
Miguel Pires $^{(1)}$, Pedro Carneiro ${ }^{(1)}$ \\ (1) Casais - Engenharia e Construção, Braga
}

\section{Resumo}

BIM é a expressão da evolução. Sendo a indústria da construção caracterizada por um desempenho muito inferior às restantes indústrias no que toca à evolução da produtividade nas últimas décadas, a implementação BIM no grupo CASAIS tem sido comprovadamente um exemplo de alavancagem na melhoria dos processos com impacto directo na redução de prazos, mitigação de incompatibilidades em fase de obra e evolução tecnológica.

Através da experiência e aumento do núcleo de Pré-Construção, foi possível ao Departamento Técnico, evoluir na sua capacidade e valências BIM.

É exposto um caso prático no contexto do desenvolvimento de uma obra, em diversos estágios. $\mathrm{O}$ envolvimento pelo Dono de Obra à CASAIS, no desenvolvimento dos projectos de especialidades numa fase ainda preliminar de licenciamento, em simultaneidade com a elaboração do projecto de execução de arquitectura, permitiu a catalisação do BIM ao longo de todo o percurso técnico desenvolvido pela equipa multidisciplinar, promovendo a participação dos diversos intervenientes (Direcção de Obra, Cliente, Arquitectos, Pré-Construção, Engenharias, Topografia, Medição, Comercial, Pós-venda, etc.).

Desde o projecto à execução da obra, é apresentado o potencial BIM em cenário real, incluindo: extração directa de quantidades para orçamentação, otimização das soluções, iteração com o procurement/compras e o recurso ao modelo BIM enquanto plataforma de comunicação entre back office e frente de obra; entre outros.

Demonstra-se aplicações concretas, ao longo do ciclo da construção, na óptica do: projectista, orçamentista, construtor e promotor imobiliário. São expostas as dificuldades relacionadas com a insuficiência de oferta de famílias BIM de fabricantes e consequente investimento técnico na produção de famílias de raiz cruciais para a modelação; as diversas abordagens/constante afinação e reajustamento da táctica para adequar o nível de detalhe ao output pretendido; as barreiras decorrentes da composição de um modelo geral por submodelos monotemáticos (arquitectura, estrutura, MEP) e até os próprios limites do software AutodeskRevit. 


\section{Caracterização do empreendimento}

Complexo destinado à habitação com um total de 52 apartamentos e área bruta de construção de $11000 \mathrm{~m} 2$, composto por dois blocos voltados para vias públicas opostas (Bloco 1 - 8 pisos e Bloco 3 - 4 pisos), um bloco interior (Bloco 2 - 2 pisos), um pátio na zona central do lote e dois pisos enterrados comuns aos três blocos para estacionamento. Pretendia-se demolir todos os elementos pré-existentes, com excepção da fachada do Bloco 1, implicando uma estrutura de contenção da mesma com cerca de $30 \mathrm{~m}$ de altura e manter e recuperar um pequeno edifício com valor patrimonial localizado no Bloco 3. Após as demolições, viria a ser executada a nova estrutura, em betão armado, incluindo os elementos tipo "mansarda" nas coberturas dos Blocos 1 e 3 .

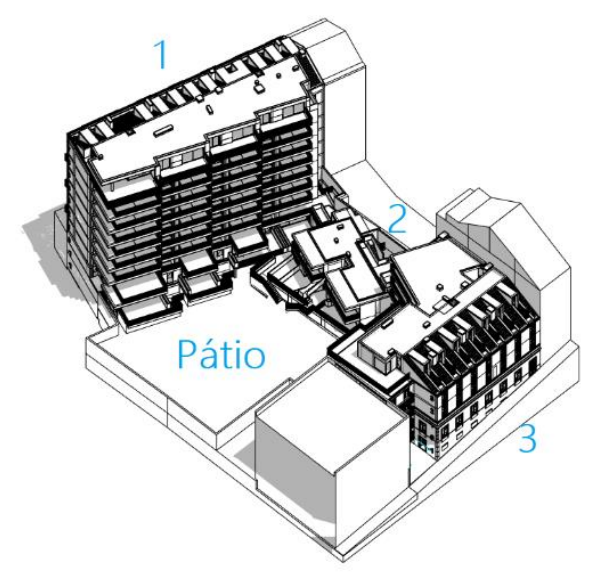

Figura 1: Vista geral empreendimento

\section{Processo comercial}

\subsection{Orçamento preliminar}

Como ponto de partida para o processo colaborativo de optimização e desenvolvimento do projecto, utilizou-se uma estimativa orçamental da Casais, baseada num projecto anterior desenvolvido pelos arquitectos projectistas. A partir desse projecto e estimativa, foi dado o seguimento descrito em seguida, com vista a alcançar metas de orçamento final, desempenho, qualidade e planeamento, conforme objectivos pretendidos pelo Dono de obra, com o mínimo impacto na desvirtuação do conceito base e standard pretendido no segmento de mercado alvo.

\subsection{Interacção com subempreiteiros}

Da parte da Casais, foram sinalizados inicialmente os capítulos do Mapa de Trabalhos e Quantidades de maior preponderância e potencial de optimização. Por exemplo, no que toca às caixilharias de alumínio e guardas metálicas (cerca de $1 \mathrm{~km}$ de guardas exteriores), foi preparado um dossier em ambiente CAD, para estudar alternativas a priori com parceiros externos cujo know-how específico pudesse melhorar as soluções e mitigar os custos neste capítulo. As alternativas foram maioritariamente aceites e incorporadas no projecto. Foram desencadeadas interacções similares no que toca às carpintarias e equipamentos, comprometendo-se também a Casais a introduzir a standardização, na fase de desenvolvimento do projecto de execução 
$\mathrm{BIM}$, de que o projecto base pudesse carecer, como módulos de armários (cerca de 250 roupeiros), biombos, armários técnicos, bases de duche, banheiras, etc. O esforço de padronização de medidas viria a acelerar a sua produção off-site ou a simplificar a execução dos elementos para ganhar também no prazo.

\subsection{Interacção com projectistas}

Para além das interacções sobre subempreitadas, foi grande o esforço de colaborativamente alcançar as melhores soluções para o projecto, quer na compatibilização da arquitectura com as especialidades quer de optimizações (AQS, materiais, pormenorização de caixilharia exterior, AVAC, iluminação, camadas de paredes exteriores/interiores, vãos interiores, etc.). Nesta e na fase 1.4, a discussão incidiu sobre os elementos 2D disponíveis à data, estando apenas previsto que o gémeo digital BIM feito pela Casais seria o receptáculo das convenções então alcançadas.

\subsection{Contribuições para o projecto base em cooperação com projectistas}

A receptividade dos projectistas foi sempre aberta a melhorias, mesmo que por vezes implicasse ajustes do projecto. Como o projecto de execução não seria desenvolvido pelos projectistas de arquitectura, para consolidação dos temas discutidos, surgiu um novo conjunto de peças desenhadas e escritas dos arquitectos, o projecto base, no qual estava toda a informação de distribuição espacial do programa e directrizes para orientar o projecto de execução.

\subsection{Medição convencional de suporte a orçamento optimizado}

Ainda em função das alterações introduzidas, foi feita uma medição integral do projecto base de suporte ao orçamento, de forma convencional $(C A D+E x c e l)$, cujo articulado construído viria a ser a referência para o projecto de execução. No ponto 3.4 é abordada a forma como se introduziu este Mapa no modelo BIM para comparação com as quantidades originais.

\section{Estrutura}

\subsection{Faseamento construtivo de contenção de fachada}

Conforme descrito no ponto 0 , foi crítico estudar o faseamento construtivo da contenção da fachada do Bloco 1, com 30m de altura e 40m de comprimento. A complexidade do projecto original suscitou a necessidade de uma simulação 3D dedicada para melhor compreensão.

Da análise do faseamento simulado, tornou-se clara a complexidade da solução e imperativo encontrar uma alternativa. A simulação 3D expôs a dificuldade de implementação, que poderia não só impactar no prazo da obra, como no próprio desempenho da estrutura definitiva do edifício na articulação com a estrutura temporária para a contenção da fachada. A alternativa que se encontrou viria a ser a executada, após validação e aprovação dos projectistas, reconhecendo a mais-valia obtida. 


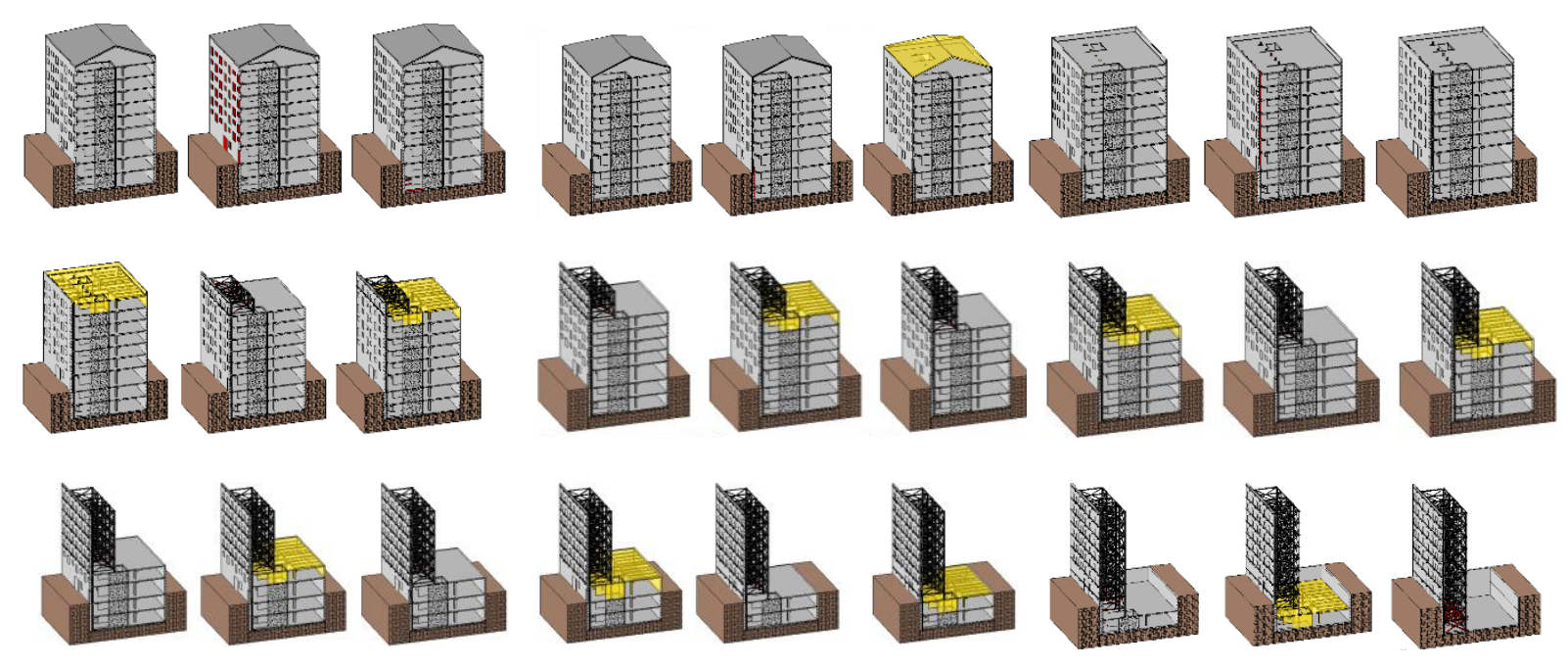

Figura 2: Faseamento construtivo da solução original de contenção de fachada (26 fases).

\subsection{Modelação 3D}

A modelação integral do projecto de estabilidade compreendeu todos os elementos da estrutura definitiva, i.e., pilares, vigas, muros, lajes maciças/aligeiradas de betão, perfis metálicos, fundações, rampas, escadas e contenção periférica. Também se introduziu os elementos envolventes e topografia, a partir do levantamento topográfico disponível. O modelo ficou indirectamente geo-referenciado por estar referenciado às coordenadas globais do levantamento geo-referenciado. A inclusão da envolvente no modelo estrutural prendeu-se com o facto de se querer ter uma base única para a modelação da arquitectura. Classificaram-se os elementos em duas vertentes: através do Mark para a identificação dos elementos conforme o projecto de estabilidade, e da criação e atribuição do parâmetro "MTQ" para relacionamento com o MTQ do projectista. No decurso da elaboração do gémeo digital de estabilidade - a pré-construção digital das peças do projecto disponíveis - decorreram inevitavelmente as mesmas dificuldades de interpretação e inconsistências que ocorreriam na sua construção real. A diferença é a capacidade e tempo útil de actuação por surgirem nesta fase, por oposição à detecção em obra. Para cada um dos cerca de 40 casos detectados pelo Núcleo de Pré-Construção, preencheu-se um boletim de pedido de esclarecimento com screenshots do modelo e remeteu-se directamente para os projectistas e/ou Direcção de Obra. O controlo fez-se em folha Excel ( $\mathrm{N}^{\mathrm{o}}$ do pedido, data de emissão/fecho, etc.).

\subsection{Medição BIM para validação das medições de projecto}

A atribuição do parâmetro "MTQ" possibilitou a extracção de quantidades volumétricas de betão para comparação com as quantidades do projectista, o que revelou discrepâncias que acabaram por ser revistas, prevalecendo as do gémeo digital. A correlação visual entre quantidades e elementos, foi feita com um código de cores, conforme a imagem seguinte. 

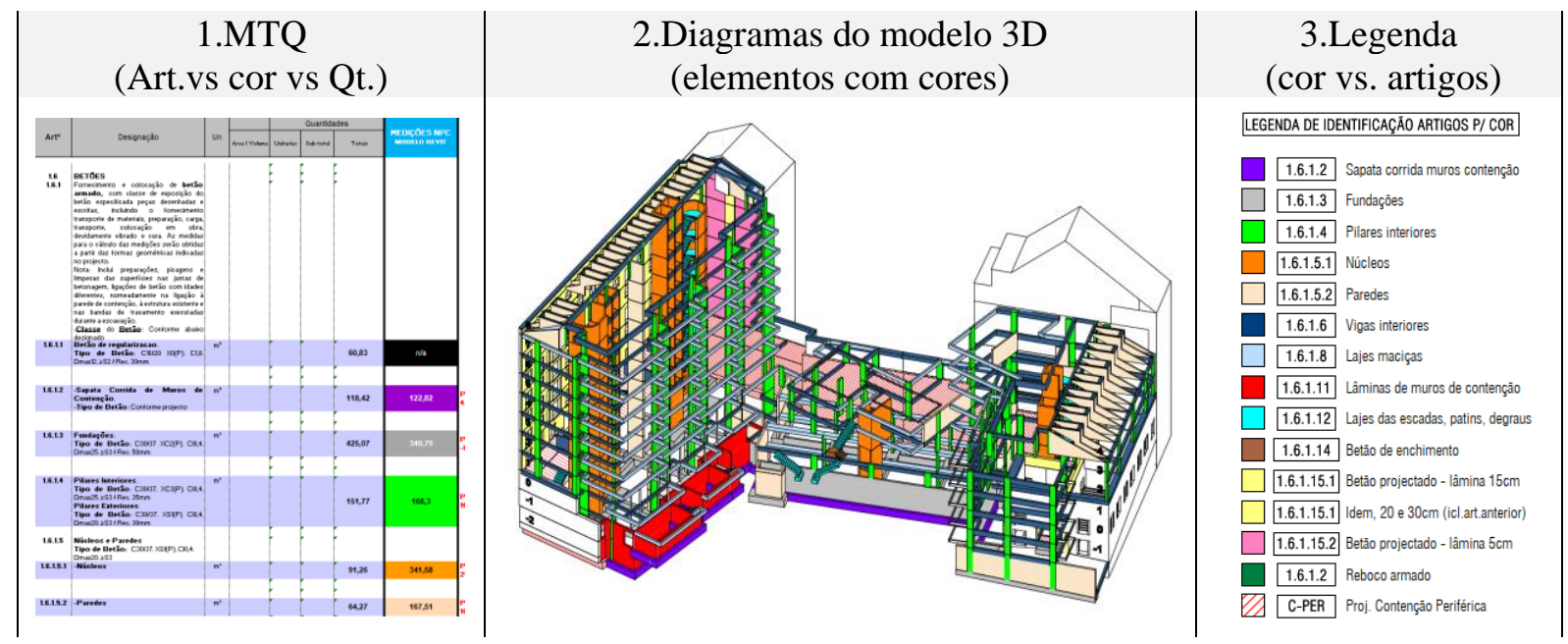

Figura 3: Inter-relação dos elementos de medição de betão a partir do modelo BIM.

\subsection{Revisões do projecto}

A proliferação de revisões do projecto de estabilidade, em função do levantamento progressivo das fundações pré-existentes aquando da escavação, implicou uma acomodação rápida das alterações na fase da elaboração do projecto de execução de Arquitectura. Genericamente, consegue-se proceder a essas alterações com maior velocidade no Revit (ou outros softwares à base de classes/categorias e parâmetros) por oposição ao que ocorreria num software de desenho 2D exclusivo (CAD). Um exemplo perfeito foi a alteração geral das espessuras das paredes estruturais dos núcleos de elevadores, que correspondeu na prática a 1 dia para modificação do tipo de paredes, previamente isolado, de 25 para $20 \mathrm{~cm}$ ( 1 minuto) e ajustes das articulações com os restantes elementos. A mesma alteração em CAD, em cada bloco/piso/tema de desenhos poderia facilmente demorar vários dias de trabalho. Esta agilidade é particularmente importante em qualquer obra com este índice de volatilidade, na qual, por exemplo, o gradual levantamento do existente implique revisões quase diárias do projecto.

\section{Arquitectura}

\subsection{Desenvolvimento do projecto de execução a partir do projecto Base}

Apesar de passadas experiências no BIM na Casais [1], este tratou-se de um processo fundamentalmente inédito na empresa. A metodologia foi delineada com a orientação para os resultados pretendidos, ou seja, o pacote de entregáveis expectável e exigido pelo Dono de Obra e capaz de suportar a execução pela Equipa de Obra. Nesta fase, transformou-se o conjunto de intenções do projecto base em elementos/soluções e dimensões reais a executar. 


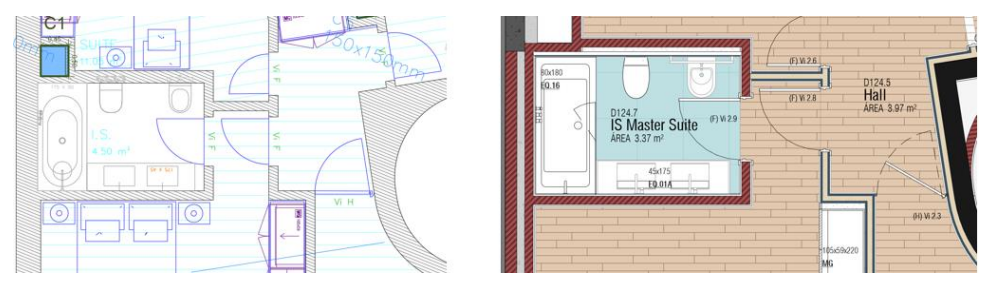

Figura 4: Projecto base vs. projecto de execução.

A colocação em prática dessas premissas, originou uma intensa interacção com todos os intervenientes para que não se desvirtuasse em demasia o projecto base e se harmonizasse simultaneamente todas as exigências técnicas e acomodação das restrições espaciais e contingências detectadas na execução do projecto de estabilidade. Para além de toda a informação geométrica expectável para a materialização da obra focada na definição de todas as camadas construtivas, a componente não geométrica, o "I" do BIM, do gémeo digital foi sendo orientada para uma necessidade imperativa de revisita do orçamento inicial no sentido de perceber qual o grau de desvio das quantidades decorrente da modelação destes elementos geometricamente mais rigorosos. Optou-se por separar os modelos Revit e trabalhar com links.

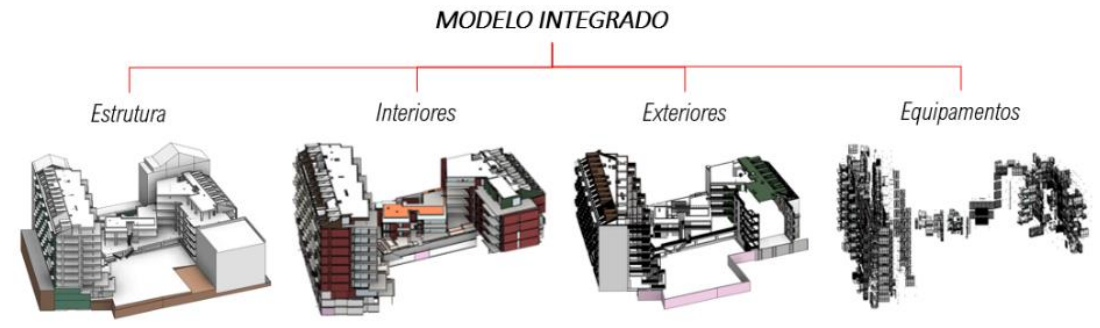

Figura 5: Subdivisão temática dos modelos Revit.

Esta separação teve por base três motivos: protege a alteração inadvertida dos modelos que não estejam momentaneamente sob trabalho (e ajuda à própria compartimentação das actividades de modelação); previne algum comprometimento da performance da máquina, já que os modelos correspondiam, na fase final, a ficheiros com 47/631/159/66 Mb; no caso dos revestimentos exteriores, uma vez que o Revit não contabiliza as porções das Walls em Wrap (apenas altera o aspecto gráfico), pretendeu-se modelar esses componentes com maior fiabilidade, inclusivamente com famílias orientadas para a extracção de quantidades num modelo dedicado. No entanto, os fenómenos da linkagem trazem outras dificuldades. De seguida, são elencados dois problemas exemplificativos e como foram contornados:

1) Funcionalidade Join é interditada entre links. Por exemplo, a ligação de uma parede (Arq.In) a um pilar (Est) não ortogonais, implica a criação de um Void para subtracção da porção da parede correspondente ao pilar. Noutros casos, é preciso dividir a parede em alvenaria + reboco até ao pilar e apenas reboco sobre o pilar. A alternativa é assumir essa coexistência geométrica, dada a impraticabilidade e morosidade desses cuidados.

2) Objectos cujos hosts são Walls não aceitam Walls em link para inserção. Por exemplo, para o modelo de equipamentos sanitários (Arq.Eq) em que imensos objectos são dependentes de Walls (Arq.In), teve que se proceder à pré-inserção dos objectos em templates de famílias face-based, gravar como novas famílias com o prefixo "_FB” e só então se conseguiu coloca-los em hosts em link. 
O balanço é favorável à divisão, mas deve ser ponderada para cada projecto e LOD pretendido a relação entre vantagens e limitações do software - podem até vir a ser atenuadas em updates.

\subsection{Famílias}

Uma vez que se pretendia alcançar um grau de rigor e de grande proximidade entre a informação modelada e o que viria a ser executado em obra, para garantir a fiabilidade geométrica dos elementos, estabeleceu-se como primeira escolha que as famílias dos produtos prescritos deveriam provir directamente dos fabricantes. Só nessa impossibilidade se pretendia recorrer à criação de famílias, suportada por guias como o OBS da NBS [2], a partir das fichas técnicas dos fabricantes. Contudo, a esmagadora maioria dos produtos não encaixou no primeiro caso, o que levou a investimento de um período considerável na elaboração e desenvolvimento de famílias, como equipamentos sanitários, vãos interiores, estores, armários, biombos, guardas, etc.
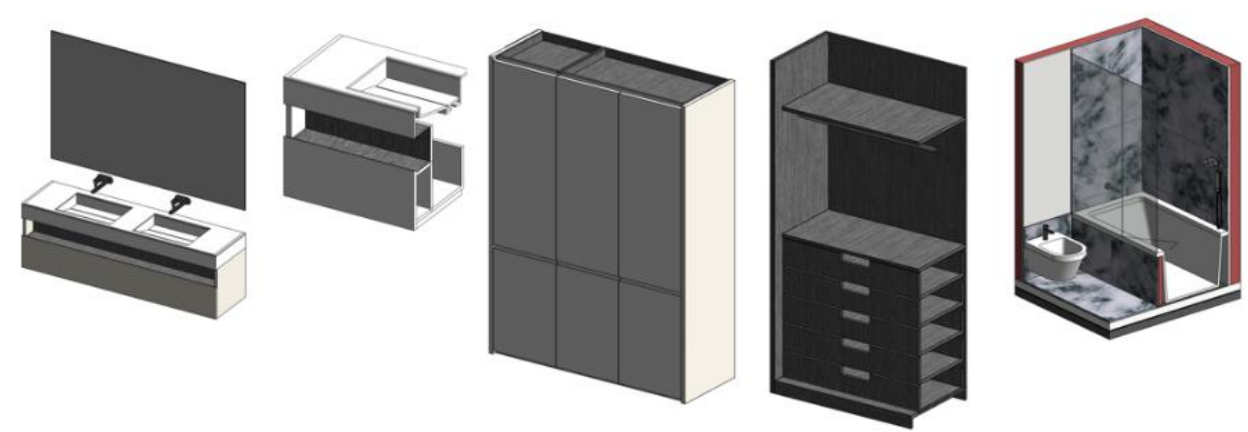

Figura 6: Exemplos de famílias desenvolvidas.

Ainda que esta tarefa possa parecer um passo lateral, algo com pouca visibilidade e consequentemente desvalorizável pelo cliente e demais intervenientes, é vital adaptar cada componente àquilo que se quer que represente no contexto do projecto ou na qualidade/quantidade da informação que contenha. Quanto ao grau de parametrização, variou entre o absolutamente estático/imutável e o extremamente versátil/adaptável com elevado número de parâmetros editáveis atribuídos.

Nos casos identificados com claro potencial de aproveitamento em futuros projectos, apesar de um esforço extra de concepção e testes de funcionalidade, fez-se o investimento na parametrização. Por exemplo, quanto ao armário roupeiro, criou-se um sistema de caixotes exterior e interior, prateleiras, gavetas, sistema de abertura, etc. tornando-se adaptável a inúmeros contextos. Foram utilizadas nested families em array para as gavetas e prateleiras em cujo número de elementos pretendidos calculam automaticamente as subdivisões, permitindo infinitas configurações. Desta forma se pretendia auxiliar também as medições. No entanto, ficou claro que, dado o tempo gasto, teria sido igualmente proveitoso desenvolver famílias mais simples (volumetrias exteriores), menos onerosas para a performance, cuja informação não geométrica fosse igualmente informativa para o TakeOff. Também se criaram famílias estáticas para os casos de produtos específicos de mercado, como torneiras, loiças sanitárias, etc.

Optou-se por classificar estes objectos através do Assembly Code para referência ao MTQ, um parâmetro "Bloco" para os localizar nos edifícios e comments para os localizar nas divisões. No cômputo geral, foram desenvolvidas cerca de 120 famílias, num esforço correspondente a 105 horas de concepção/desenvolvimento e 33 horas de testes e refinamento do seu emprego. 


\subsection{Modelo BIM para consolidação de inputs de todos os intervenientes}

A fase do desenvolvimento do projecto de execução caracterizou-se por uma dinâmica interacção entre Projectistas, Dono de Obra, Núcleo de Pré-construção e Equipa de Obra. Não se optou por um CDE nos termos da norma ISO 19650-1 [3], uma vez que o PEB de Arquitectura foi uma iniciativa da Casais. Ainda assim, o gémeo digital transformou-se no agregador e representação momentânea de cada fase, um timelapse de fotografias nas quais se ia antevendo o resultado de todos os inputs:

- Respostas dos projectistas aos às dúvidas derivadas da análise do projecto base;

- Respostas dos projectistas no seguimento de incompatibilidades dos projectos (no caso das incompatibilidades MEP, fez-se entre os exportáveis do modelo BIM e os CAD dos projectos);

- $\quad$ Revisões do projecto de estabilidade (ver ponto 2.4);

- Alterações económicas de alternativas na fase pós-orçamento;

- Personalizações das habitações dos clientes finais mediados pelo Dono de Obra;

- Apoios específicos a temas levantados pela equipa de obra (ver ponto 3.5).

Se, por um lado, não se pode classificar este gémeo digital como federado porque foi sendo modelado pela mesma entidade, a sua lapidação conjunta foi sendo feita, essa sim, de forma federada, na intenção de ir vendo digitalmente construído o somatório das decisões.

\subsection{Extracção automática de quantidades e revisão do mapa de trabalhos e quantidades} Tirando partido de uma funcionalidade nativa do Revit, o Assembly Code, foi transposto e formatado para txt $o$ MTQ do projecto e carregado para o Revit, para que no navegador do AC do programa fosse mais fácil a atribuição de cada elemento a um artigo do mapa. De referir que isso é possível já que o $A C$ é um parâmetro nativamente atribuído a quase todas as categorias de elementos. A partir dessa atribuição e com um ou outro parâmetro diferenciador para ajudar a filtrar os Schedules, como o "Bloco" a que cada elemento estava afecto, gerou-se um conjunto de tabelas baseadas nos critérios de medição das quantidades do orçamento, para comparação em ambiente Excel: A) com as quantidades originais; B) com as quantidades resultantes de cada revisão do projecto, mapeando o impacto nos custos de cada alteração. O processo Revit/Excel foi feito por exportação de csv, com a desvantagem de ter que ser feita artigo-a-artigo, mas que, por outro lado, permitiu imediatamente detectar grandes discrepâncias e ponderar se seriam decorrentes de alterações de projecto ou de algum fenómeno de erro na operação de extracção.

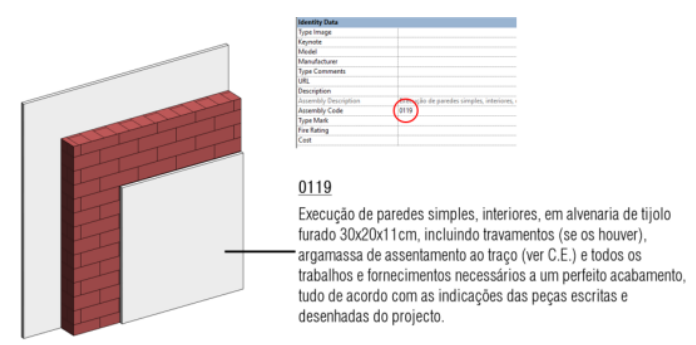

Fig.7: Utilização do Assembly Code para ligação ao articulado

Para garantia da fiabilidade da informação, em vários casos duplicou-se o método de extracção, tendo sido descobertas algumas fragilidades do software. Por exemplo, quanto aos rodapés, ao 
parâmetro length de um elemento rodapé não é subtraída a porção correspondente às zonas de vãos interiores, ainda que o join entre esses elementos o faça desaparecer visualmente. Para solução, criou-se um calculated parameter igual ao volume dividido pela área da secção, já que ao volume o Revit remove a porção do vão, obtendo assim o real comprimento. Outra dificuldade foi a obtenção das áreas de tectos sob escadas, porque não é possível associar a inclinação de um ceiling a um objecto de referência. A solução encontrada foi usar o Paint para pintar as superfícies com materiais com nomes diferentes por bloco (por exemplo, "Tectos sob Escada 1 - Bloco 1") directamente no modelo estrutural, para obtenção da área a revestir/pintar.

\subsection{Incorporação de processos de apoio à execução da obra}

Para fornecer preparações úteis para a obra, para além dos desenhos com view templates dedicados aos temas como alvenarias, pavimentos, tectos, etc. foram também incorporadas no modelo informações solicitadas pela Equipa de Obra que esta considerasse relevante para dar seguimento ao trabalho. Assim, incluiu-se na modelação aspectos à partida não planeadas, como caixas de estore embutidas, espessuras de cola, trabalhos de juntas de cerâmicos, etc.

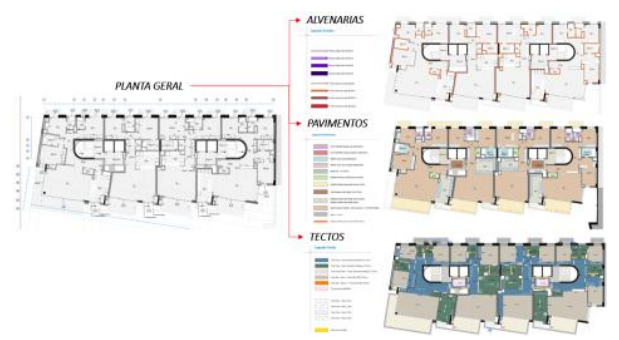

Fig.8: multiplicidade de outputs a partir do mesmo modelo.

\subsection{Worksharing}

O worksharing foi posto em prática numa fase de maturação dos modelos, na qual o processo a acelerar foi o de tagging, cotagem e preparação de layouts para exportação. Apesar de serem tarefas não exigentes do conhecimento específico/aprofundado do projecto, implicam um elevado consumo temporal, pelo que se colocou vários técnicos nessa tarefa, no modelo central.

\subsection{Output de elementos técnicos para validação/execução}

Após exportação das sheets, foram feitas várias emissões para os projectistas, Dono de obra e Fiscalização, para validação e estabilização das várias interacções. Uma vez atingido o resultado consensual entre todas as partes, foi entregue o pacote final de elementos à Equipa de Obra, em vários formatos ( $d w g, p d f$ e $d w f)$ bem como os modelos IFC para consulta/navegação dos modelos 3D (ponto 4.1). Uma dificuldade sentida foi a de exportação de $p d f$ e $d w f$ vectoriais e não rasterizados. Esse fenómeno, para além do dano gráfico, desperdiça - no caso do $d w f$ - a informação não geométrica contida e consultável directamente nos elementos. Após investigação, foi detectado que elementos que acrescentam riqueza gráfica como sombras e backgrounds forçam o software a fazer a rasterização. Ou seja, para preservar a informação e vectorização é inevitável sacrificar algum aspecto dos desenhos e das vistas 3D.

\subsection{Output de elementos para visualização}

Com base no gémeo digital, criou-se uma tour virtual de navegação do mesmo em estado mais "realista" para ajudar a obra a prever o estado final e auxiliar momentos de indecisão dos 
clientes finais. Recorreu-se a um software extra, no qual se fez e renderizou o enriquecimento cosmético do modelo (p.ex. vegetação), alcançando um produto menos técnico e mais estético.

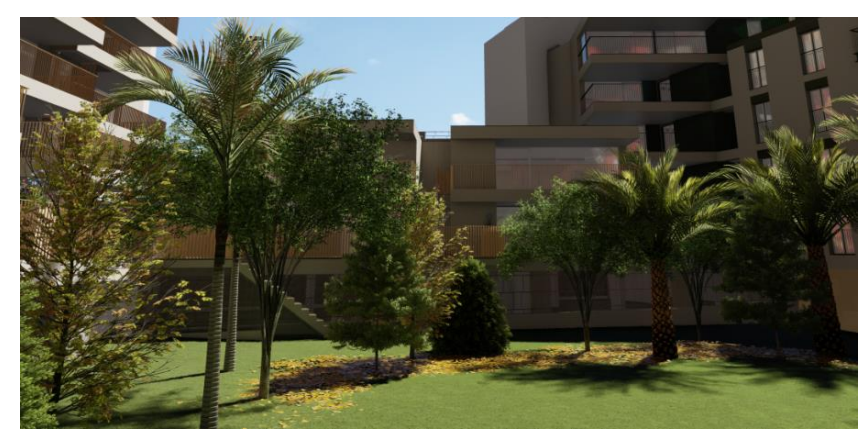

Fig.9: Visualização 3D do exterior do caso de estudo

\subsection{Testes de compatibilidade com Equipa de Obra}

Surgiram problemas de compatibilidade, nomeadamente relacionadas com a interoperabilidade de software da Equipa de Obra no manuseio dos $d w g$ exportados do Revit. Em resposta a essas questões, foi estudado o efeito de cada opção de exportação com os feedbacks da Equipa de Obra para cada hipótese. Assim, atingiu-se um grau de compatibilidade superior, com desenhos mais manipuláveis, ainda que tenha ficado por resolver, por exemplo, a editabilidade de tramas.

\subsection{Monitorização de actividades}

Como forma de vir a ter uma noção mais detalhada das actividades de modelação e respectiva distribuição temporal, uma vez que se tratou de um processo sem precedente, houve a preocupação de registo diário dos macro-temas e horas dedicados. Através dos dados recolhidos, foi possível gerar uma análise clara dos temas mais exigentes que evidenciou onde se poderia intervir com mais impacto na optimização de actividades e distribuição do tempo.
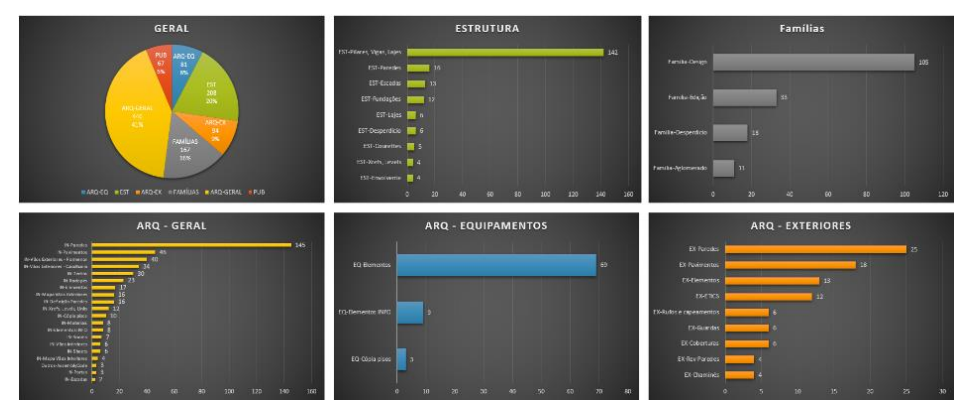

Fig.10: Gráficos de distribuição temporal das actividades do caso de estudo.

\subsection{Elaboração de guião para processos análogos}

A inexistência de um PEB inicial para orientação do processo, suscitou a necessidade de um "guia" para os seguintes como forma de condensar todas as aprendizagens, recomendação de práticas de modelação e extracção de quantidades e definição de milestones para ir avaliando o cumprimento/desfasamento entre o plano e o estado real do desenvolvimento do projecto. Estrutura do guia elaborado: 1.Arranque/decisões iniciais; 2.Modelação/links; 3.Criação de famílias; 4.Checklist da sequência de modelação; 5.Boas/más práticas; 6.Plug-ins/Dynamo recomendados; 7.Glossário. 


\section{Construção}

\subsection{Utilização do modelo BIM para apoio à execução}

Para colocar o gémeo digital do lado da Equipa de Obra, fora do Revit, para permitir a navegação e consulta do modelo e informação criados, foram experimentadas várias plataformas (avaliando a capacidade de comportar anotações, guardar vistas, integrar links, relacionar directamente desenhos 2D com modelo 3D, etc.). Entre elas, A360 e Dalux BIM Viewer, nas quais a Equipa de Obra pôde consultar, para além da informação geométrica para dissipação de dúvidas, a informação contida nos elementos como cotas altimétricas, áreas, materiais, características de vãos (dimensões, configurações, tipos de abertura nos parâmetros de tipo e instância), complemento de pedidos de esclarecimento através de anotações feitas em screenshots no decurso da exploração virtual, etc. O feedback da Equipa de Obra foi crítico para validação ou afastamento de cada solução, mas ainda hoje este é um assunto em aberto.

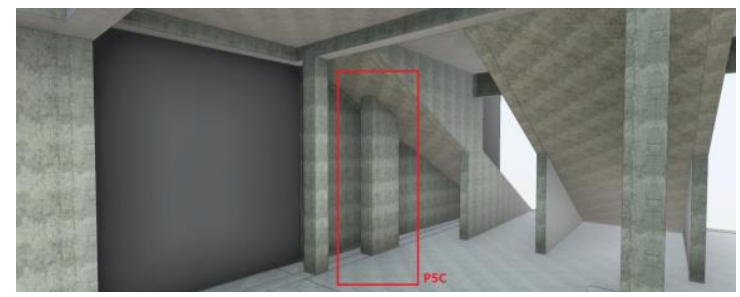

Fig.11: Navegação do modelo para esclarecimento e detecção de problemas

\subsection{Utilização do modelo BIM para planeamento}

Para além dos usos virtuais, uma das aplicações mais criativas pela obra foi a manipulação de imagens 3D do modelo para planeamento através da introdução de datas e manchas de cor.

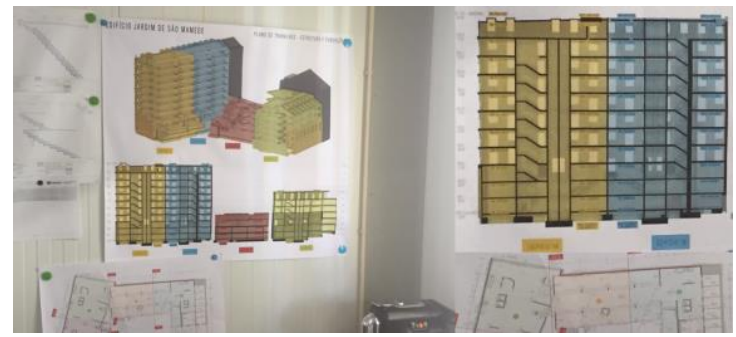

Fig.12: Fotografias do contentor/estaleiro Casais no caso de estudo.

\section{Futuro}

Sobressaiu a pluralidade de utilizações da metodologia BIM e casos nos quais já demonstrou ser uma mais-valia na fase comercial, concepção e execução. Mas também são claros a margem para optimização e os limites actuais da tecnologia e da transmissão dos modelos virtuais a todas as equipas. Um dos vectores de melhoria é o aumento da utilidade do gémeo digital e da sua informação pela Equipa de Obra, quer para consulta, organização de processos/documentos, anotações, gestão de tarefas, planeamento, etc. Só se poderá alcançar o tão urgente aumento de produtividade do sector [4], garantindo um maior aproveitamento dos modelos BIM pela Equipa de Obra, também para justificar o elevado investimento que a sua elaboração acarreta. 


\section{Referências}

[1] Lima, A.C, "Upgrade of an industrial building: BIM model of the as-built situation and evaluation of modifications", 2015.

[2] RIBA Enterprises Limited, "NBS BIM Object Standard", 2014.

[3] ISO 19650-1:2018 - Organization and digitization of information about buildings and civil engineering works, including building information modelling (BIM) - Information management using building information modelling — Part 1: Concepts and principles.

[4] McKinsey Global Institute,"Reinventing construction: a route to higher productivity", 2017. 